\title{
Fábulas da vida obscura: imagens técnicas e
} anonimato ${ }^{1}$

Vera Lúcia Follain de Figueiredo²

1 A primeira versão deste texto foi apresentada no seminário A visibilidade dos anônimos, promovido pelo Grupo de Pesquisa Mídia e Narrativa, da Pontifícia Universidade Católica de Minas Gerais (PUC-MG), em Belo Horizonte, nos dias 06 e 07 de novembro de 2013. 


\section{Resumo}

A partir do final do século XVIII, o homem comum é cada vez mais objeto do olhar não só das instituições de controle da ordem social, mas também da técnica, da ciência e da arte. O esforço de desvelamento visando neutralizar a força ameaçadora das massas urbanas, no entanto, conviveu sempre com a contrapartida das estratégias de ocultamento, como as conspirações, os complôs. Considerando que, com o avanço das tecnologias da comunicação, a oposição entre exibir e ocultar tornou-se cada vez mais tênue, o artigo discute o alcance da dicotomia visibilidade/invisibilidade quando se trata de estabelecer relações entre as práticas culturais e a política.

\section{Palavras-chave}

Visibilidade, imagens técnicas, política, história.

\section{Abstract}

From the late eighteenth century, institutions of social control increasingly focused their attention on the ordinary man, that was also the focus of technique, science and art. However, the unveiling effort to neutralize the threatening force of an urban mass always coexisted with strategies of concealing, such as conspiracies and schemes. With the advancement of communication technologies, the opposition between showing and hiding has become more tenuous. This article debates the extent of visibility/invisibility dichotomy when it comes to establishing a correlation between cultural practices and politics.

\section{Keywords}

Visibility, technical images, politics, history. 
Os termos que compõem a dicotomia visibilidade/invisibilidade não são necessariamente contrários nem tampouco definem lugares fixos. Ver sem ser visto é um atributo do poder, ao mesmo tempo em que não ser visto pode significar a exclusão de toda e qualquer esfera de participação na vida da sociedade. Num certo sentido, a visibilidade do anônimo não Ihe garante a voz, ao contrário, a exposição de sua imagem pode ser um modo de silenciá-lo. Portanto, falar da invisibilidade dos anônimos é falar também da sua visibilidade, ou melhor, da necessidade de torná-Ios visíveis pelas instâncias de controle e vigilância ou de torná-los visíveis como integrantes dos espetáculos que dão sustentação ao poder: são os anônimos que constituem a massa, a matéria moldável, que serve, por exemplo, ao processo de estetização da política na primeira metade do século $X X$ europeu.

Com a modernidade, os anônimos são cada vez mais colocados em cena, seja como atores da história, seja como vítimas da própria história, como ocorreu no momento da Revolução Francesa e do massacre do proletariado insurgente em junho de 1848. Caracterizada pela ambivalência, a modernidade descreveu um movimento de atração/repulsão pelos que compunham, primeiro, a multidão e, depois, o povo ou a massa: a arte acompanhou tal movimento. Uma obsessiva busca de transparência pontuou o realismo do século XIX, cujos antecedentes próximos podem ser buscados no surgimento do gênero das fisiologias: estas, como destacou Benjamin (1994, p. 36), ao descreverem de maneira amistosa os tipos que circulavam nas feiras e bulevares, procuravam afastar as inquietações provocadas pela vida na cidade grande, convencendo o leitor da sua própria capacidade de adivinhar a origem, o modo de vida e o caráter dos estranhos que dividem com ele o espaço das ruas: "Quem vê sem ouvir fica muito mais inquieto do que quem ouve sem ver", diz Simmel (1994, p. 36), chamando a atenção para o fato de as relações na cidade se distinguirem pela preponderância da atividade visual sobre a auditiva.

Tributária dos aperfeiçoamentos das técnicas de imprensa e da maior circulação dos jornais, a ficção literária exerceu um papel decisivo nesse momento 
em que o outro, o desconhecido que circulava nas grandes cidades era objeto de curiosidade, medo e compaixão. O romance realista invadia a vida privada dos pequenos burgueses, entrava em suas casas para desvelar a intimidade familiar, como fez H. Balzac, adentrando os círculos domésticos para decifrar os segredos das aparências sociais. O baixo mundo da cidade que tanto assustava como fascinava a burguesia garantiu o sucesso estrondoso de folhetins como Os mistérios de Paris, de Eugène Sue, cujo primeiro capítulo foi publicado em 1842. Sue vestia-se de operário e perambulava pelos bairros pobres da cidade para observar o baixo mundo da miséria, das barricadas, dos criminosos, mas também dos agiotas e dos burgueses avarentos, com o objetivo de, através de sua narrativa, descortinar para os leitores, de maneira fiel e rigorosa, as dores, os vícios e as virtudes daquela camada da população urbana cujos costumes excêntricos e as desgraças eram invisíveis para as classes abastadas. Paralelamente a esse tipo de literatura que se alimentava do exotismo do mundo miserável dos proletários, mas também se nutria da compaixão que suas vidas inspiravam, a narrativa policial tranquilizava o público perscrutando sinais aparentemente insignificantes para recompor identidades ocultas que ameaçavam a ordem. Por um outro viés, o romance histórico tematizava o heroísmo do homem comum, que passara a ver a história como algo que lhe concerne em termos imediatos, já que uma série de transformações sociais, políticas e econômicas, ocorridas naquele momento, envolviam as massas populares num processo ininterrupto de mudanças com consequências diretas sobre a vida de cada indivíduo.

Desde a virada do século XVII para o XVIII, como observou Foucault, o ocidente viu nascer toda uma fábula da vida obscura, uma arte da linguagem cuja tarefa já não era cantar o improvável, mas pôr em evidência o que não é evidente. Durante muito tempo, segundo o filósofo, a vida de todos os dias, na sociedade ocidental, só pôde ter acesso ao discurso quando atravessada e transfigurada pelo fabuloso, o heroísmo, as aventuras, a providência e o poder, fugindo ao vulgar (1992, p. 124). Com a modernidade, surge uma nova ética do discurso literário pautada pela determinação de desentranhar a parte mais noturna e mais cotidiana da existência, empenhada na revelação do mais comum dos segredos: 


\begin{abstract}
A literatura faz assim parte daquele grande sistema de coação por meio do qual o Ocidente obrigou o cotidiano a pôr-se em discurso; todavia, ela ocupa aí um lugar especial: obstinada a procurar o cotidiano por debaixo dele próprio, a ultrapassar os limites, a levantar brutal e insidiosamente segredos, a deslocar regras e códigos, a fazer dizer o inconfessável, ela terá tendência a pôr-se fora da lei, ou pelo menos a tomar a seu cargo o escândalo, a transgressão ou a revolta (FOUCAULT, 1992, p. 127).
\end{abstract}

Consolidado como gênero na primeira metade do século XIX, período heroico da burguesia, quando esta incorporava a defesa da emancipação universal à sua ideologia, o romance, segundo Lukács, começa a mudar de rumo após o massacre dos operários em 1848. Para o filósofo, ao atacar as massas, a Ilustração se enfrenta com seus limites sangrentos e a transparência da narrativa é perdida com o sangue do proletariado (2011, p. 254). Retomando, a seu modo, o argumento de Lukács, Barthes, em O grau zero da escritura, afirma que, em torno de 1850, ocorre a conjunção de três fatos históricos: "A modificação da demografia europeia, a substituição da indústria têxtil pela indústria metalúrgica" e a "secessão (consumada pelas jornadas de junho de 48) da sociedade francesa em três classes inimigas, isto é, a ruína das ilusões do liberalismo" (1971, p. 71). Para Barthes, até então, era a própria ideologia burguesa que dava a medida do universal, preenchendo-o sem contestação. Diz o autor: "O escritor burguês, único juiz da infelicidade dos homens, não tendo diante de si nenhum outro para olhá-lo, não se via dilacerado entre sua condição social e sua vocação intelectual. Daí por diante, essa mesma ideologia só apareceria como uma ideologia entre outras possíveis: o universal escapaIhe" (1971, p. 71).

A literatura incorporava a consciência culpada e o escritor, a partir daí, passava a assumir ou renegar, através da escritura, sua condição burguesa: "Cada vez que o escritor traça um complexo de palavras, é a própria existência da Literatura que se põe em questão; o que a modernidade permite ler, na pluralidade de suas escrituras, é o impasse de sua própria história" (BARTHES, 1971, p. 72). 
Nesse mesmo contexto, avanços técnicos e científicos forneciam instrumentos que alimentavam o desejo de onividência das sociedades modernas. A própria iluminação artificial nas grandes cidades funcionava como um antídoto contra a obscuridade, eliminando as zonas de sombra onde podiam se abrigar temporariamente parcelas da população marginalizadas pela nova ordem urbana. Confundir-se com a multidão tornava-se, então, a maneira mais eficaz de esconderse, de dissolver a identidade em meio ao grupo uniforme dos congêneres, como pressente o personagem de Edgar Alan Poe, no conto O homem da multidão, que circulava sem rumo na cidade em sua caçada ao desconhecido. O fascínio das luzes, que prometiam transparência, complementou-se com o surgimento da fotografia e do cinema. A primeira tanto dissociava imagem e referente, circulando independentemente do modelo, quanto, em seu uso instrumental, neutralizava os perigos da mobilidade, da circulação incessante, último refúgio dos que não queriam ser vistos. Tornando-se ferramenta da investigação policial, a fotografia fixava identidades, atrelava a imagem ao nome: "À mobilidade da multidão urbana e à fantasmagoria de identidades e nomes falsos, o sistema legal opôs uma circulação regulada de informações e imagens", como assinalou Gunning (2001, p. 73). Por sua parte, o cinema punha em evidência o anonimato, levando o espectador a ver a si mesmo como elemento de uma massa urbana em perpétua transição. Com a consolidação das artes mecânicas, surgiria o que Jacques Rancière chamou de regime estético das artes, que levava à ruína o regime de representação tal como era constituído até então: "Um sistema em que a dignidade dos sujeitos comandava a dignidade dos gêneros de representação", que "reservava a tragédia para os nobres, a comédia para a plebe" (2005, p. 47). Daí em diante o anônimo tornava-se tema de arte, em detrimento das histórias dos grandes feitos e dos grandes personagens, instaurando-se um novo regime de verdade, a partir de uma nova racionalidade do banal e do obscuro que se contrapõe às ordenações aristotélicas (2005, p. 56).

O medo das massas, vistas inicialmente como aglomeração informe e inextricável, gerou a necessidade de esquadrinhá-la, de constituir um saber 
sobre a maneira como elas se constituem, sobre como se relacionam com a autonomia do indivíduo. Em 1895, Le Bon publicava Psicologia das massas. No livro, de grande repercussão - retomado, inclusive, por Freud em texto da década de 1920, intitulado Psicologia das massas e a análise do eu -, Le Bon adverte que, segundo a história nos ensina, quando as forças morais de uma sociedade deixam de atuar, a dissolução final é efetuada "pelas multidões inconscientes e brutais, qualificadas justamente de bárbaras", acrescentando:

As civilizações foram criadas e têm sido guiadas, até agora, por una reduzida aristocracia intelectual, jamais pelas massas, que não têm poder mais que para destruir. Seu domínio representa sempre uma fase de desordem. Uma civilização implica regras fixas, uma disciplina, o trânsito desde o instintivo até o racional, a previsão do porvir, um grau elevado de cultura, condições totalmente inacessíveis às massas, abandonadas a si mesmas (LE BON, 2005, p. 18).

No entanto, tal esforço de desvelamento-iluminação visando neutralizar a força ameaçadora das massas urbanas conviveu sempre com a contrapartida das estratégias de ocultamento, com as conspirações: quanto mais intensos foram os conflitos, mais densosforam os segredos.

Nesse sentido, a invisibilidade também se constituiu numa arma. É desse pressuposto que parte Ricardo Piglia em sua Teoría del complot. Para ele, "o complô supõe uma conjura e é ilegal porque é secreto, sua ameaça implícita não deve atribuir-se à simples periculosidade de seus métodos, mas ao caráter clandestino de sua organização: como política, postula a seita, a infiltração, a invisibilidade" (2006, p. 1, tradução nossa) ${ }^{3}$. Segundo o escritor argentino, o excesso de informação produz um efeito paradoxal, porque aquilo que não se sabe passa a ser a chave da notícia, num mundo onde todos se obrigam a buscar a chave escondida que permita decifrar a realidade. Daí que a paranoia, antes de se tornar um caso clínico, seria uma saída para a crise de sentido. Ler entre linhas, como se houvesse algo cifrado, seria por 
si só um ato político: o censor leria desse modo e também o conspirador, os grandes modelos do leitor moderno (2006, p. 1). O complô implicaria a própria ideia de revolução:

O partido leninista foi fundado sobre a noção de complô, e conecta complô e classe, complô e poder. Gramsci fez ver que o concepto de organização em Marx estava ligado à primitiva organização dos clubes jacobinos eàs conspirações secretas de pequenos grupos. Guevara, desde logo, exaspera essa linha com sua noção de grupo guerrilheiro, isolado em território inimigo, como uma base móvel da sociedade futura (2006, p. 1, tradução nossa) $)^{4}$.

A noção de complô, conforme a teoria de Piglia, permitiria também pensar a política de Estado, que tem sua face clandestina nos serviços secretos, nas formas de controle, cujo objetivo central seria registrar os movimentos da população. Além disso, o Estado anuncia, desde sua origem, o fantasma de um inimigo poderoso e invisível. Portanto, pelo viés do segredo, os mecanismos do poder e do contrapoder se assemelhariam: construir um complô contra o complô do Estado seria a resposta do sujeito que se sente socialmente manipulado por forças às quais atribui características de uma conspiração destinada a controlálo. O conspirador contra o poder procuraria apagar suas pegadas, opondo-se à lógica social da visibilidade. Sua aparição deve ser instantânea e explosiva: estaria, então, sempre disposto a abandonar seu nome, "fazer-se anônimo, converter-se em ninguém" (PIGLIA, 2006, p. 5).

Para o autor, no romance como gênero, o complô substituiu a noção trágica de destino: certas forças ocultas definem o mundo social e o sujeito é um instrumento dessas forças que não compreende. O romance teria feito a política entrar na ficção sob a forma do complô:

A diferença entre a tragédia e o romance parece estar ligada a uma mudança de lugar da noção de fatalidade: o destino é vivido sob a forma de um complô. Já não são os deuses os que decidem a sorte,

$4 \quad$ "El partido leninista está fundado sobre la noción de complot, y conecta complot y clase, complot y poder. Gramsci hizo ver que el concepto de organización en Marx estaba ligado a la primitiva organización de los clubes jacobinos y a las conspiraciones secretas de pequeños grupos. Guevara, desde luego, exaspera esa línea con su noción del grupo guerrillero, aislado en territorio enemigo, como una base móvil de la sociedad futura". 
são as forças obscuras as que constroem maquinações que definem o funcionamento secreto do real. Os oráculos mudaram de lugar, é a trama múltipla da informação, as versões e contraversões da vida pública, o lugar visível e denso de onde o sujeito lê cotidianamente a cifra de um destino que não alcança compreender (PIGLIA, 2006, p. 2, tradução nossa $)^{5}$.

Seguindo este raciocínio, Piglia considera que as chamadas vanguardas históricas, com sua política de intervenção localizada, com sua percepção conspirativa da lógica cultural, concebiam a produção de poder como uma guerra de posições, propondo-se a assaltar os centros de controle cultural e alterar hierarquias: o modelo de sociedade seria a batalha, não o pacto, o estado de exceção e não a lei (2001, p. 4). Contra a falsa ilusão de acordo e consenso, as vanguardas propunham a provocação à ordem e, opondo seita à maioria, optavam por uma política escandalosa e hermética para fazer frente ao falso equilíbrio do mercado e da circulação de bens culturais. Vista por esse ângulo, a vanguarda artística seria uma prática antiliberal, uma versão conspirativa da política da arte que supõe sempre a necessidade de construir um complô para quebrar o cânon, negar a tradição estabelecida e impor outra hierarquia e outros valores: a vanguarda estabeleceria um corte entre mundo cultural e democracia, que apresenta como antagônicos, opondo-se ao gosto da maioria e ao saber submetido ao consenso (PIGLIA, 2006, p. 4).

O próprio relato de um complô, na perspectiva do autor, já faria parte do complô, estabelecendo-se uma relação concreta entre narração e ameaça: o complô poderia ser considerado como uma ficção potencial, uma intriga que se trama e se põe em circulação, cuja realidade seria sempre duvidosa $(2006$, p. 1).

Tal relação entre complô e narrativa nos remete de imediato para o papel voluntário ou involuntário desempenhado pelas mídias na circulação das intrigas conspiratórias. A título de exemplo, cabe lembrar que o papel das mídias na

5 "La diferencia entre tragedia y novela parece estar ligada a un cambio de lugar de la noción de fatalidad: el destino es vivido bajo la forma de un complot. Ya no son los dioses los que deciden la suerte, son fuerzas oscuras las que construyen maquinaciones que definen el funcionamiento secreto de lo real. Los oráculos han cambiado de lugar, es la trama múltiple de la información, las versiones y contraversiones de la vida pública, el lugar visible y denso donde el sujeto lee cotidianamente la cifra de un destino que no alcanza a comprender". 
divulgação de relatos que já constituem complôs é um dos temas do filme $O$ capital, de Costa Gravas (França, 2012), baseado no romance de mesmo nome, do francês Stéphane Osmont. O mundo financeiro, as transações bancárias, são representados, na obra, sob o signo do complô. As disputas pelo poder levam o presidente de um banco francês a contratar um investigador para descobrir as tramas daqueles que o rodeiam, inclusive as intenções ocultas que levaram à sua própria indicação para o cargo. As notícias plantadas na mídia pelos homens do mundo financeiro seguem os planos arquitetados pelos especuladores, com consequências desastrosas para a vida econômica dos países e dos indivíduos que neles trabalham.

Reforça-se, assim, a ideia das disputas políticas e econômicas como combate realizado no campo da fabricação de narrativas. Nesse sentido, poder e contra poder podem assumir o papel de artistas criadores. Esta é uma das teses desenvolvidas também por Éric Michaud, embora focalize a relação entre arte e política por um outro prisma, diferente do adotado por Piglia. Em seu livro A estética nazi: uma arte da eternidade, Michaud volta-se para a sobreposição da figura do ditador e do artista, para a junção da arte e da vida na retórica do nazismo, que atribuía a Hitler a grande missão de esculpir a realidade. Parte do princípio de que, na primeira metade século XX, afirmou-se a ideia da legitimação do poder pelo gênio artístico, isto é, a convicção de que o homem de Estado seria também um artista. Lembra, então, as palavras de Goebbels, em 1931, no texto Combate em Berlim: "A massa não é para nós mais que um material informe. É pela mão de um artista que da massa nasce um povo e do povo uma nação (2012, p. 13)". Dentre outros exemplos retirados da retórica dos ditadores naquele momento, o autor recorda as palavras de Mussolini, considerado o escultor da nação italiana, ao inaugurar, em 1922, uma exposição do grupo Novecento: "Falar como artista entre os artistas, pois a política trabalha sobre o mais difícil e o mais duro dos materiais, o homem" (2012, p. 14).

Segundo Michaud, naquele contexto, os ditadores justificavam normativamente sua existência por uma identificação de princípio entre atividade artística e atividade política. O nazismo teria se apropriado do mito 
da superioridade do artista, da ideia de força brutal da arte que rompe todas as convenções, propalada pelas vanguardas, e do abismo existente entre as propostas estéticas vanguardistas e as massas, para se colocar como o grande artífice da espiritualização do povo e da transformação das massas em obra de arte. Para ele, na base da glorificação da arte pelo nazismo está o pensamento de Nietzsche, privilegiando-se não o despojamento de si do artista em sua obra, mas a vontade de poder (2012, p. 56).

Por um outro viés, Rancière, em A partilha do sensível, considerando que a história das relações entre partidos e movimentos estéticos é, antes de mais nada, a história de uma confusão, às vezes complacentemente entretida, em outros momentos violentamente denunciada, destaca a existência de duas ideias de vanguarda: uma estratégica e outra estética. A primeira apontaria para a existência de uma inteligência política na qual se concentrariam as condições essenciais de transformação, implicando a noção topográfica e militar da força que marcha à frente. A segunda se enraizaria na antecipação estética do futuro, anunciaria experiências sensíveis inovadoras, próprias de uma comunidade de homens livres ainda por vir: seria uma revolução estética que produziria uma nova ideia de revolução política. Estas duas ideias não estariam separadas em dois campos diversos, o da arte e o dos movimentos políticos, porque a própria vanguarda política se dividiria entre a concepção estratégica e a estética.

A leitura feita por Rancière das relações entre vanguarda e política, na qual também se podem encontrar ecos do pensamento nitzscheano, decorre de sua convicção de que a arte e a política têm uma origem comum, já que a política seria, como a arte, uma forma de organizar o sensível, de construir formas de inteligibilidade e de dar visibilidade. Discorda, então, de Benjamin quando este afirma que o exercício do poder teria se estetizado num momento específico, isto é, nas manifestações do Terceiro Reich. Para Rancière, o poder sempre lançou mão de formas espetaculares de mise-en-scène. Mas não só o poder: toda manifestação política, toda insurreição, teria um caráter teatral. Assim, com o objetivo de demonstrar o vínculo essencial entre política e teatro, 
retoma, em texto da coletânea Momentos políticos, a imagem de uma barricada, na insurreição dos trabalhadores franceses de junho de 1848, publicadas num jornal inglês. A partir dessa fotografia, na qual os insurgentes pareciam se exibir vaidosamente, desenvolve o argumento de que, ao ocupar as ruas, os operários se apropriavam de um espaço, que em geral serve à circulação dos indivíduos e das mercadorias, para situar ali outra cena e redistribuir papéis. Diz o autor: "O espaço de circulação dos trabalhadores se converte em um espaço de manifestação de um personagem esquecido nas contas do governo, o povo, os trabalhadores ou qualquer personagem coletivo" (2010, p. 54).

Como se pode depreender da leitura de seus textos, dentre as três bandeiras da revolução francesa - liberdade, fraternidade e igualdade - Rancière elege a igualdade como base para a transformação das sociedades, como pressuposto que viabilizaria a conquista da liberdade e da fraternidade. Em função disso, confere à ficção um papel privilegiado, já que constituiria o espaço por excelência da mobilidade dos papéis, da multiplicidade de identidades, alargando o limite dos possíveis. Partindo do princípio de que o mundo imaginário da ficção não se opõe ao mundo real, considera que a política começaria com a duplicidade dos papéis instaurada pela ficção, que configura novos cenários. Para ele, se Platão "denunciou tão fortemente a tragédia, não foi simplesmente porque poetas eram pessoas inúteis ou suas histórias eram imorais. Foi porque percebeu a solidariedade entre ficção teatral e política democrática" (2010, p. 55). Não poderia haver, do ponto de vista de Platão, seres duplos na cidade, onde cada um devia ocupar-se exclusivamente de seus próprios assuntos: "E não só os atores de teatro seriam seres duplos. O trabalhador que deixa de trabalhar com sua ferramenta para converter-se em ator de um personagem como povo também é um ser duplo", diz Rancière (2010, p. 55).

O caráter teatral das barricadas dos tempos heroicos é contraposto ao que ocorreria no mundo contemporâneo, no qual os governantes elaborariam sua imagem como marca, mas renunciariam ao que era a essência espetacular da política: a retórica pública. Diz o autor: 
As ficções televisivas são antificções que nos apresentam a personagens como nós, que se desenvolvem num cenário parecido com aquele desde o qual o miramos, e que expõem problemas similares aos nossos, similares aos que expõem, em outro horário, os testemunhos da realidade (RANCIÈRE, 2010, p. 57).

A sociedade na qual vivemos, que leva a domicílio tanto as guerras sangrentas como as pequenas preocupações cotidianas, isto é, a ficção similar à realidade, não seria, para o filósofo, a sociedade do espetáculo descrita por Debord, mas a da antifantasia, a que diz, junto com os governantes, que só existem a realidade, as mercadorias, as pessoas que as produzem, as vendem e as consomem. A mensagem da sociedade da negação das aparências seria: "Deixem de fazer teatro. Já não estamos em tempos de teatro" (DEBORD, 2010, p. 58).

Quando assinala o entrelaçamento da estética da política com a política da estética, Rancière volta à questão da relação entre arte e vida, que ele terá de ajustar, não sem dificuldades, à sua defesa da distância entre palco e plateia, entre espectador e ator, desenvolvida principalmente em $O$ espectador emancipado. Nesse livro, rejeita a ideia de que a eficácia política da arte será recuperada pela abolição da separação entre a cena da atividade artística e a da vida coletiva. Nega a eficácia política do teatro sem espectadores, do teatro como uma forma de comunidade vivente, como assembleia ou cerimônia da comunidade, afirmando a necessidade de suspensão de toda relação direta entre a produção das formas da arte e a produção de um efeito político determinado sobre o público. No entanto, em artigos que compõem o livro Momentos políticos, considerando que o povo representaria nas manifestações populares um papel diverso do que the foi reservado pelo poder, afirma a teatralidade como traço inerente à manifestação política do povo nas ruas, e acrescenta: "A política começa com a capacidade de fingir sua própria dor, de compor uma máscara, uma fábula que faz com que essa dor possa ser compartida mais além do medo e da compaixão. Porque o sofrimento fundamental é o estado daquele que não pode fingir sua dor" (RANCIÈRE, 2010, p. 38). 
O ativismo político abordado pelo viés da teatralidade aproxima-se, dessa forma, do teatro sem espectadores, do teatro que se propõe como coro do povo em ato, ao qual Rancière, em $O$ espectador emancipado, nega eficácia política, enfatizando a separação entre a arte, como um domínio próprio, e outras formas de experiência sensível, embora considere que é esta mesma separação que, paradoxalmente, Ihe garante o caráter político.

Tudo que foi dito até aqui permite, então, afirmar que complô e teatro das ruas, invisibilidade e espetáculo, arte e vida, o subterrâneo e o aparente, o direito ao oculto e o direito à imagem, constituem balizas que pautaram as tensões da modernidade: balizas que, no século XXI, ganham outras configurações, tornandose ainda mais cambiantes. A dimensão política, que a década de 1990 relegara ao segundo plano em meio à euforia com a globalização da economia, volta a ser discutida, mas, sintomaticamente, é abordada como conquista de lugares e não como movimento projetivo da história, isto é, a política se espacializa.

Nesse quadro, não é de se estranhar que a ideia de revolução seja considerada obsoleta. O termo revolução é indissociável da dimensão temporal, tanto na sua acepção primeira, de retorno - para designar o movimento cíclico dos astros - quanto na acepção que a modernidade Ihe conferiu, como ruptura radical que instaura um novo tempo, um novo começo. Sabe-se que os modelos utópicos dos séculos XVI e XVII seguiam a lógica do deslocamento espacial. Os países ideais de Morus e Campanela não se encontravam no futuro, mas distantes no espaço. Somente nos séculos XVIII e XIX haverá a temporalização completa da história, e é neste momento que o conceito de revolução deixa de implicar a ideia de regeneração e adquire a dimensão da novidade, da criação de uma forma de governo totalmente diferente, comprometida com a libertação da opressão: a utopia torna-se ucronia.

Ao se definir hoje, como faz, por exemplo, Rancière, a política como um modo de divisão de ocupações, o que fica de fora é a prospecção temporal. A política como arte do dissenso descreve uma luta permanente pela conquista de espaços travada por parte daqueles que não têm visibilidade, na qual cada 
momento vale por si: nem utopia nem ucronia, mas heterotopia. Procura-se evitar a ideia de marcha histórica orientada para o futuro, a ideia de necessidade histórica. Ressalta-se, então, a reordenação intermitente do que é visível e enunciável e, em função disso, a ficção ocupa o lugar proeminente antes reservado para a história, porque se considera que é o trabalho da ficção que cria dissensos, que "muda os modos de representação do sensível e as formas de enunciação, mudando os marcos, as escalas e os ritmos, construindo novas relações entre a aparência e a realidade, o singular e o comum, o visível e seu significado" (RANCIÈRE, 2012, p. 67).

Se levarmos em conta que, tanto para Rancière quanto para Piglia, o problema da relação entre a arte e a política não é a transição da ficção ao real, pois estaríamos diante de duas maneiras de produzir ficções, pode-se dizer que os autores se aproximam quanto à concepção de política. Para ambos, o que caracterizaria a ficção dominante, a ficção consensuada, é precisamente negar seu próprio carácter de construção ficcional, fazendo-se passar pelo real em si mesmo. Entretanto, as estratégias propostas pelos dois teóricos na luta contra a ficção do poder são diversas. Rancière toma partido do espetáculo que se contrapõe ao fatalismo da realidade cotidiana sempre igual a si mesma, com seus lugares fixos, imutáveis. Piglia faz da própria invisibilidade a trincheira que viabiliza a luta quando o desequilíbrio de forças é extremamente desfavorável para o lado dos que se insurgem contra a injustiça. Face a esse desiquilíbrio, os anônimos resistiriam criando ficções contra a ficção do consenso que o poder instituído deseja instaurar. Contra a lógica social da visibilidade reinante em nossa época, o complô consistiria em formas antissociais e antiestatais de luta para modificar as relações de força. No entanto, a conspiração implicaria uma política baseada "na debilidade extrema, na ameaça contínua de ser descoberto, na iminência de uma derrota e na construção de redes de fuga" (2001, p. 5).

Já para Rancière, a visibilidade é a condição necessária para dar início a qualquer embate que vise a conquista da igualdade. Visibilidade é aí tanto estratégia - como a ocupação dos espaços públicos para fins não previstos pelos 
governos, a ocupação das ruas pela multidão insatisfeita - quanto o resultado final pretendido, isto é, a conquista dos direitos de cidadania, de ser visto como igual e, portanto, ser incluído entre aqueles que contam.

Nesse ponto, torna-se inevitável retornar ao que Piglia chamou de exercício da leitura paranoica. Na atualidade, o papel de detetive paranoico desempenhado pelo leitor moderno tende a se acentuar, já que, cada vez mais, a oposição entre exibir e ocultar perde a nitidez: a conspiração se exibe nas redes sociais, as máscaras, ao mesmo tempo, ocultam e conferem visibilidade, o direito à imagem é reivindicação de ser visto e, contraditoriamente, de ser dono da própria imagem, impedindo sua exibição ou negociando essa mesma exibição, fazendo da imagem uma mercadoria. Assim, mesmo que rejeitemos aideia de que a conspiração é o motor da história, pelo caráter paralisante que pode assumir atribuindo ao povo o papel de eterna marionete nas mãos de pequenos grupos, a consciência crescente de que a mídia nos apresenta versões dos fatos nos leva a suspeitar de que tais versões são movidas por interesses que desconhecemos. Diante, por exemplo, das manifestações sociais que têm ocorrido, no mundo, nos últimos cinco anos, desmoralizando o vaticínio do fim da história, a expectativa esperançosa é tensionada pela revelação, cada vez mais frequente, de tramas secretas urdidas num passado recente, que vem à tona a partir do vazamento de informações sigilosas. Passando ao largo dessa tensão, alguns falam com grande otimismo de uma interação horizontal sem lideranças, vendo, na multidão reunida nas ruas, o somatório de indivíduos descontentes, embora, contraditoriamente, falem também da adesão aos movimentos como contágio viral pelas redes. Contrapõem o que consideram a autonomia da comunicação em rede ao controle das grandes mídias e, privilegiando esse aspecto, nivelam todos os movimentos, independentemente dos contextos históricos em que estão inseridos.

No entanto, na perspectiva paranoica, assumida como gesto político, o permanente exercício da desconfiança suscita uma série de perguntas. Podese indagar se o culto da horizontalidade, indissociável do entusiasmo com o 
desenvolvimento tecnológico, ao qual se atribuem efeitos democratizantes, não implicaria o esquecimento de que toda técnica é um meio a serviço dos homens, sendo eles que Ihe conferem destino político. Seguindo essa linha, pergunta-se até que ponto as hierarquias dissolvidas pela tecnologia digital têm contribuído para a dissolução de outras hierarquias, como as que se assentam na estrutura injusta do sistema econômico. Sociedades alicerçadas nos saberes transversais da internet, avessas a toda e qualquer liderança, seriam necessariamente mais igualitárias? Também sempre se pode questionar, em tempos de práticas de espionagem no mundo digital, até que ponto as redes constituem esse espaço de liberdade e autonomia em relação aos poderes instituídos?

Ainda valeria indagar se a propalada descrença na confiabilidade das grandes mídias reduziu o seu papel na cena política: para uma grande maioria de pessoas, o teatro das ruas só existe quando representado no teatro da grande imprensa. O que se oculta nessa dobra, o que está por trás do que se mostra? Daí derivam outras perguntas. Como transformar a visibilidade em uma arma eficaz? Como evitar que o complô se transforme no exercício estéril de fabricar contraficções desconectadas de um projeto efetivo de transformação da realidade? Mas se a ideia de que o amanhã confere sentido ao hoje e ao ontem caiu em descrença, como falar em projeto? Voltamos, por esse caminho, à questão da temporalidade, aos referenciais do passado que assaltam, para o bem ou para o mal, nossa percepção do presente, assim como também o presente é assaltado pelas perspectivas futuras, que implicam estratégias ou agendas de ação política.

Foi aos referenciais do passado que Jacques Derrida recorreu, na década de 1990, para se contrapor à euforia neoliberal que levou Francis Fukuyama a proclamar o fim da história. Com o objetivo de combater a ideia tranquilizadora de que teríamos atingido a democracia perfeita e, portanto, teríamos entrado numa era pós-histórica, o filósofo evocou a obra de Karl Marx: mais especificamente o "espectro de Marx", que, segundo ele, teria atemorizado a Europa ao longo dos dois últimos séculos e ainda estaria sendo conjurado até hoje, não só no Velho Continente. 
O termo espectro, tal como utilizado, em perspectiva histórica, pelo próprio Marx, prestava-se à representação figural da intervenção do passado no presente e, na direção contrária, remetia também à iminência do futuro, cuja presença já poderia ser pressentida. Esta última situação fica evidente na primeira linha do Manifesto Comunista, onde se lê: "Um espectro ronda a Europa - o espectro do comunismo". Em síntese, lançava-se mão da figura do espectro para designar uma luta travada, na esfera da história, entre a recorrência do passado e a abertura para o novo.

Derrida chama a atenção para esse fato de que o fantasma, no Manifesto, era uma presença por vir, ou seja, era o que, na representação ideológica da Europa, por aquele tempo, só tinha aparência de um espectro, mas que deveria se tornar, no futuro, uma realidade presente, ou seja, viva. Diz o filósofo: "O manifesto invoca, reclama esta apresentação da realidade viva: é preciso fazer com que no porvir, este espectro - e, em primeiro lugar, uma associação de trabalhadores obrigada ao segredo até por volta de 1848 - torne-se uma realidade e uma realidade viva" (1991, p. 139).

Enfatizando a ideia de que o Manifesto pressupunha a materialização do espectro, isto é, a passagem do segredo para a visibilidade, o filósofo formula a hipótese de que a crença na distinção entre fantasma e realidade efetiva, entre simulacro e presença real, explicaria a obsessão de exorcizar espectros, que pontuaria o pensamento de Marx.

Retomado na ótica da filosofia da desconstrução, de sua proposta de diluição dos binarismos que balizaram a metafísica ocidental, o termo "espectro" torna-se, no livro de Derrida, uma categoria operadora da fusão entre o visível e o invisível, num giro que transforma não só o próprio Marx, mas também o futuro anunciado por ele, em renitente assombração que atormenta a todos por seu caráter mesmo de assombração. Assim, ao voltar ao passado visando resgatar a promessa de emancipação, como antídoto ao conformismo reinante, Derrida recorre ao paradigma da visualidade para valorizar o caráter reiterativo das imagens fantasmáticas, espectrais, não a sua superação no porvir, como 
pretendia Marx. Propõe uma nova historicidade, comprometida coma afirmação da promessa emancipatória, mas como promessa, não como programa.

A teoria do outro como espectro serve, então, de mote para que se conclua esse artigo convocando um outro fantasma: o do sentido da história, tomando-se o vocábulo "sentido" na acepção de direção, que implicaria a escolha de caminhos a serem tomados. Não seria esse fantasma que se quer exorcizar quando se abordam as desigualdades sociais pelo viés da visibilidade/invisibilidade, destacando a iteratividade, o caráter intempestivo dos acontecimentos contra a ideia de processo histórico? Para esconjurá-lo, Rancière fala de "momentos políticos", definidos como aqueles em que a temporalidade do consenso é interrompida. Para afugentá-lo também, Derrida, ao reler Marx, ressalta a sua permanência entre os vivos, mas como espectro, isto é, como aparição provocadora, dissociada do projeto de sociedade que propôs. 


\section{Referências}

BARTHES, R. O grau zero da escritura. São Paulo: Cultrix, 1971.

BENJAMIN, W. Charles Baudelaire: um lírico no auge do capitalismo. São Paulo: Brasiliense, 1994.

DERRIDA, J. Espectros de Marx: o Estado da dívida, o trabalho do luto e a nova Internacional. Rio de Janeiro: Relume Dumará, 1994.

FOUCAULT, M. O que é um autor? Lisboa: Vega, 1992.

GUNNING, T. "O retrato do corpo humano: a fotografia, os detetives e os primórdios do cinema". In: CHARNEY, L.; SCHWARTZ, V. R. (Org.). O cinema e a invenção da vida moderna. São Paulo: Cosac Naify, 2001.

LE BON, G. Psicologia das massas. Lisboa: Ésquilo, 2005.

LUKÁCS, G. O romance histórico. São Paulo: Boitempo, 2011.

MICHAUD, E. La estética nazi: un arte de la eternidade. Buenos Aires: Adriana Hidalgo, 2012.

PIGLIA, R. "Teoría del complot". Revista Casa de las Américas, Havana, no 245, out/dez de 2006. Disponível em: http://www.casa.cult.cu/publicaciones/ revistacasa. Acessado em: 20 nov. 2007.

RANCIÈRE, J. A partilha do sensível. São Paulo: Editora 34, 2005.

. O espectador emancipado. São Paulo: Martins Fontes, 2012.

. Momentos políticos. Buenos Aires: Capital Intelectual, 2010.

SIMMEL, G. apud BENJAMIN, W. Charles Baudelaire: um lírico no auge do capitalismo. São Paulo: Brasiliense, 1994. 